\title{
Pattern of Congenital Heart Disease in Infants of Diabetic Mother
}

\author{
SHORMINARA FERDOUSI ${ }^{1}$, FERDOUSUR RAHMAN SARKER ${ }^{2}$, NASIM JAHAN ${ }^{3}$, NURUNNAHAR FATEMA ${ }^{4}$
}

\begin{abstract}
Background: The aim of the study was to unveil the prevalence of different types of Congenital Heart Disease (CHD) through echocardiogram and to perceive the utility of Echocardiogram in diagnosis of CHD in Infant of Diabetic Mother (IDM).

Methodology: This explorative study was carried out at Combined Military Hospital (CMH) Dhaka, Bangladesh over a period of one year from July 2004 to June 2005. The study was done on 56 neonates of gestational diabetic mother irrespective of their gestational age and birth weight who were delivered at $\mathrm{CMH}$. All the patients were evaluated by echocardiography by an expert pediatric cardiologist of the same institute within 7 days of delivery.
\end{abstract}

Results: Out of 56 IDM 5.2\% was normal. The most common Echo-cardiographic finding was patent Foramen Ovale (60.71\%). Other different Echocardiographic findings were patent Ductusarteriosusin 31 (55.3\%) cases, Hypertrophic Cardiomyopathy in $12(21.42 \%)$ cases and ASD in $6(10.71 \%)$ cases. Some other uncommon findings include Ventricular Septal Defect (VSD), Tricuspid Regurgitation(TR) and Right ventricular hypertrophy $(R V H)$.

Conclusion: These findings of CHD of Infant of Diabetic Mother (IDM) could demonstrate that Echocardiogram might be used as an effective tool to diagnose CHD for the IDM.

Key Words: Infant of diabetic mother, Echocardiography, Cardiac Abnormality, Congenital Heart Disease.

\section{Introduction:}

Diabetes Mellitus is a syndrome of diverse genetic, environmental and pathogenic origin characterized by hyperglycemia resulting from impaired insulin secretion and/or effectiveness. ${ }^{1}$ Gestational diabetes mellitus (GDM) is carbohydrate intolerance of variable severity at onset which is first recognized during the pregnancy. ${ }^{2}$ GDM complicates $1 \%$ to $3 \%$ of all pregnancies. ${ }^{3}$ Different studies showed that congenital anomalies occur 3 - 5 times more commonly in the Infant of Diabetic Mother (IDM) than in the general population ${ }^{4,5,6}$. These anomalies include Neural Tube Defects, Caudal Regression Syndrome, Renal Malformations and Congenital Heart Disease. The risk

1. Lt. Colonel, Child Specialist, Combined Military Hospital, Mymensing, Bangladesh

2. Lt Colonel, Paediatric Cardiologist, Combined Military Hospital Dhaka, Bangladesh

3. Assistant professor, Department of Neonatology, Ad-din Medical College, Dhaka

4. Colonel, Paediatric Cardiologist, Combined Military Hospital, Dhaka, Bangladesh

Correspondence: Dr. Shormin Ara Ferdousi, Lt Colonel, Child Specialist, Combined Military Hospital, Mymensing, Bangladesh, Email:shormin@gmail.com of fetal cardiac malformations in IDM has been found to be significant, most notably Atrial Septal Defect (ASD), Ventricular Septa Defect (VSD), Transposition of the Great Vessels, Truncus Arteriosus, Coarctation of Aorta and Hypertrophic Cardiomyopathy. This condition is reported in significant number of IDM and is thought to be secondary to high fetal insulin levels as a result of maternal hyperglycemia and may be a further manifestation of fetal "Macrosomia". Affected patients are usually asymptomatic but occasionally present immediately following delivery with decreased cardiac output, respiratory distress and other symptoms of cardiac failure requiring aggressive medical therapy. Most series have reported spontaneous resolution in survivors within 4 - 6 months but there are reports of patients continuing to have abnormal dimensions into the second year of life. ${ }^{6}$

Most of the studies in this context have been done in North America and Europe and rarely in other rich countries. In a large population based case-control study (Baltimore-Washington study) showed that the overall risk of structural CHD was 3.2 times more in 
diabetic mother than non-diabeticmother. ${ }^{9}$ To date, there are very few significant studies to find out the pattern of cardiac abnormalities including structural cardiac anomalies or hypertrophic cardiomyopathy in IDM in the Bangladeshi population. So the objective of this study was to investigate and portray the infants of diabetic mothers for learning and documenting the prevalence and spectrum of CHD and the utility of echocardiography in the early diagnosis of CHD.

\section{Methodolgy:}

This observational study was done in Combined Military Hospital, Dhaka from July 2004 to June 2005. All the pregnant cases were identified and recorded from the onset of the each pregnancy. Initially all mothers were evaluated regularly for gestational diabetes during their antenatal checkup like three monthly in first trimester, twice in a month in second trimester and weekly in third trimester. Fifty six newborn babies of newly established gestational diabetic mother(GDM) irrespective of gestational age who agreed to participate by informed written consent were enrolled in this study. GDM was diagnosed as per diagnostic criteria of American Diabetic Association Guideline ${ }^{8}$. Previously diagnosed cases of diabetes melitus (DM) and with other comorbid diseases like CKD, hepatitis, heart failure and tuberculosis were excluded. After enrollment, detail ante natal history, time of diagnosis of the diabetes, medications for control of DM etc. were recorded. After delivery capillary blood glucose test was done within first 6 hours by glucometer and APGAR score was evaluated at 1, 5 and 10 minutes. According to the score necessary measures were taken to resuscitate the sick neonates. Thorough physical examination with special focus on cardiac and extra-cardiac abnormalities was given. Each IDM underwent chest X-ray, electrocardiography (ECG) and echocardiography within 7 days of delivery. Experienced pediatric cardiologist done the echocardiogram within seven days of stable neonate by 2DcolourDoppler in M mode (Siemens acuson cv 70) at CMH Dhaka. Data was collected and appropriate computer program was compiled for data analysis and bring out the tables. As the study recalled, SPSS PC 17 Computer Program was used where in the relevant cases, tables were generated with Multiple Response and thus the total number of cases sometimes went over $100 \%$ as some IDMs possessed more than one deformity.

\section{Results:}

A total of 56 neonates with diabetic mother were analyzed where $34(61 \%)$ of the IDM found was female and the rest 22(39\%) was male, highest 33.9\% IDM were seen of 38 weeks of gestational age, whereas, $23.2 \%$ IDM were of 40 weeks (Figure 1). Most of the mothers were in the age range of 20-40 years. Among others $10(17.8 \%)$ were at age less than 20 and $2(1.6 \%)$ mothers were more than 40 years of age(Figure 2). Most of the mothers were at term 39(75.4\%), few were pre and post term which was $21.5 \%$ and $7.3 \%$ respectively (Figure 3 ). Mean gestational age was 38.39 weeks. Among the all neonates about 22 (42.6\%) were more than $4000 \mathrm{gm}$ (Figure 4). Regarding different neonatal findings,

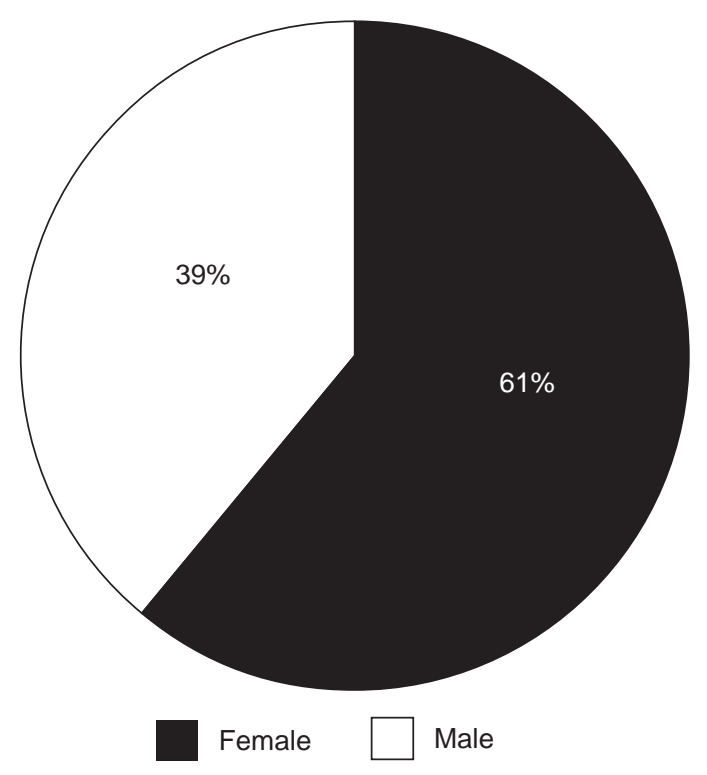

Fig.-1: Distribution of Sex of the baby:

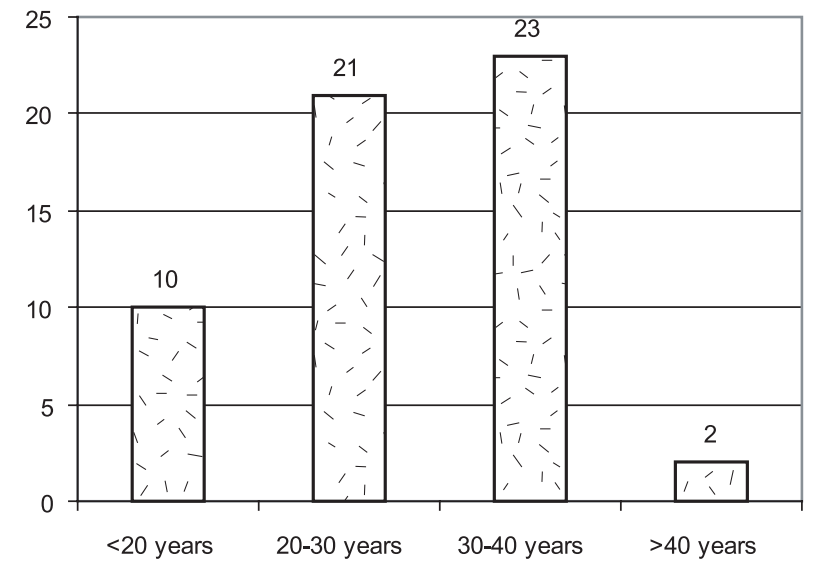

Fig.-2: Age ranges of the mother 


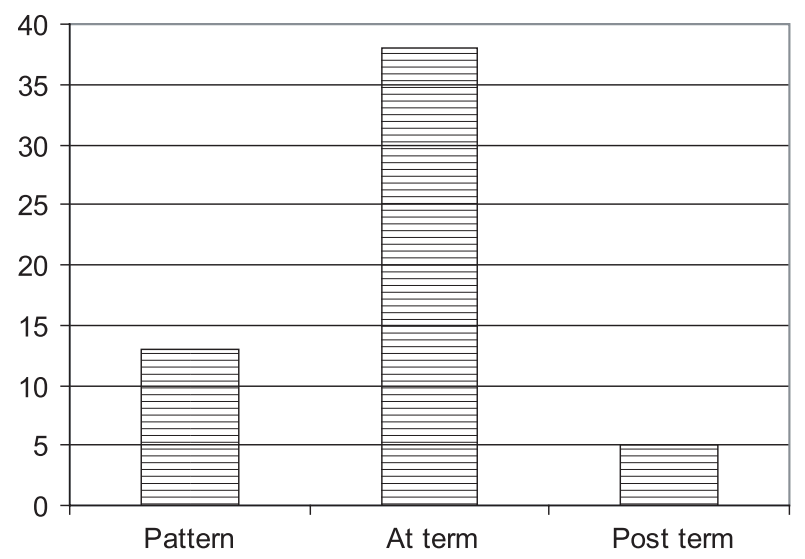

Fig.-3: Gestational age of the mothers

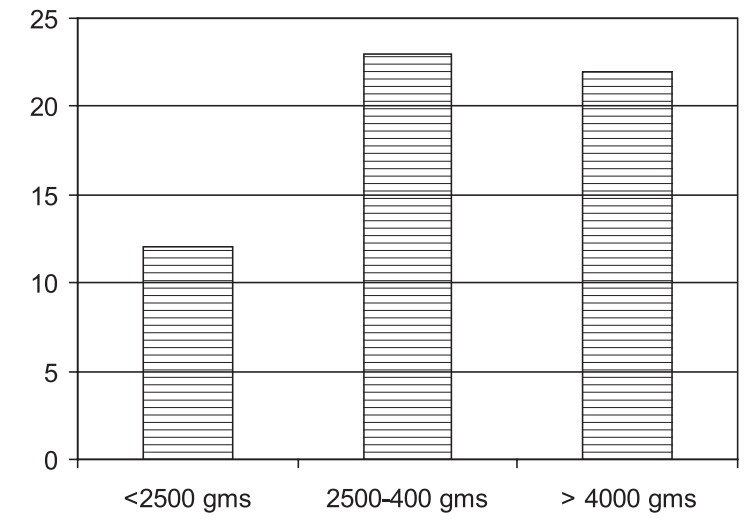

Fig.-4: Birth weight of the neonates

Macrosomia was found in 34(68\%) neonates, Perinatal Asphyxia was found in $11(22 \%)$ neonates, respiratory distress was common among $44(88 \%)$ of neonates and one patient found to have cyanosis (Table 1). In echocardiography Patent Ductus Arteriosus was found in $31(55.3 \%)$, patent Foramen Ovale was found in 34(60.71\%), Hypertrophic Cardio Myopathy was found in $12(21.42 \%)$ and ASD was found in $6(10.71 \%)$ of neonates with some other uncommon findings like VSD, TR and RVH (Table-II).

Table-I

Neonatal findings

\begin{tabular}{lcc}
\hline Neonatal findings & Number $(\mathrm{n}=56)$ & $\%$ \\
\hline Macrosomia & 34 & $60.7 \%$ \\
Perinatal Asphyxia & 11 & $19.6 \%$ \\
Cyanosis & 1 & $1.72 \%$ \\
Respiratory distress & 44 & $74.8 \%$ \\
Extra-cardiac congenital & 4 & $5.25 \%$ \\
anomalies & & \\
\hline
\end{tabular}

*(Multiple Response $)=$ Some IDMs possessed more than 1 deformity
Table-II

Echocardiographic findings of the neonates (Multiple Response)

\begin{tabular}{lcc}
\hline $\begin{array}{l}\text { Echocardiographic } \\
\text { findings }\end{array}$ & $\begin{array}{c}\text { Number } \\
(\mathrm{n}=56)\end{array}$ & $\%$ \\
\hline Patent Ductus Arteriosus & 31 & $55.3 \%$ \\
Patent Foramen Ovale & 34 & $60.71 \%$ \\
Hypertrophic Cardio Myopathy & 12 & $21.42 \%$ \\
ASD & 6 & $10.71 \%$ \\
VSD & 2 & $3.54 \%$ \\
TR & 2 & $3.54 \%$ \\
RVH & 1 & $1.752 \%$ \\
\hline
\end{tabular}

*(Multiple Response)=Some IDMs possessed more than 1 deformity

\section{Discussion:}

Congenital cardiovascular malformations form the common birth defects, affecting around 6-8 per 1000 live births. ${ }^{6}$ In most cases the cause is unknown although some are genetic in origin and a few are known to have an environmental cause. Only $1 \%$ of cases are caused by maternal diseases. ${ }^{7}$ Maternal diabetes is known to have a Teratogenic effect on the cardiovascular system with a reported risk of malformation in published studies of 1.7-4.0\%. ${ }^{8}$

In the present study different Echocardiographic findings of the neonates where Patent Ductus Arteriosus was found in 31(55.3\%), patent foramen ovale was found in 34(60.71\%), Hypertrophic Cardiomyopathy was found in 21(37.5\%), ASD was found in $6(10.71 \%)$ of neonates with some other uncommon findings like TR.

Studies of antenatal echocardiography and diabetic pregnancy also report an excess of cardiovascular malformations. Gladman and colleague ${ }^{9}$ identified fetal heart disease in seven of 328 diabetic pregnancies. Four pregnancies resulted in live birth, giving prevalence at live birth of congenital heart disease of 1.2\%. MeyerWittkopf and colleagues ${ }^{10}$ reported a prevalence of fetal cardiac abnormalities of $3.1 \%$ in diabetic mothers. Five babies were live born, giving a live birth prevalence of $1.5 \%$. The authors concluded that the "increased risk" of cardiovascular malformation in infants of diabetic mothers was an indication for fetal echocardiography.

In common with previous studies, ours included babies with Persistent Ductus Arteriosus, Patent Foramen 
Ovale and Atrial Septal Defect recognized in infancy. Both of these are usually asymptomatic in the infant or young child and both are more commonly recognized beyond infancy. In a previous study it was found that $47 \%$ of cases of Persistent Ductus Arteriosus and $41 \%$ of Atrial Septal Defects were diagnosed in children in the first 12 months of life compared with $80 \%$ of all other cardiovascular malformations. ${ }^{11}$ Infants born to diabetic mothers may be subjected to greater scrutiny and may therefore be more likely to have asymptomatic cardiovascular malformations recognized. Despite that, it can be seen from table 2 that Atrial Septal Defect, Patent Foramen Ovale and Persistent Ductus are not overrepresented in the spectrum of cardiovascular malformations.

Our prospective population based study of infants of diabetic mothers has confirmed the increased risk of cardiovascular malformations and the greatly increased risk of some specific malformations, notably Atrial Septal Defect, Patent Foramen Ovale and Persistent Ductus. It supports existing recommendations that all pregnant women with diabetes should be offered a specialist fetal echocardiogram. This advice is reinforced by published evidence that antenatal diagnosis of cardiac malformations leads to an improved postnatal outcome.

Our prospective population based study of infants of diabetic mothers has confirmed the increased risk of cardiovascular malformations and the greatly increased risk of some specific malformations, notably Atrial Septal Defect, Patent Foramen Ovale and Persistent Ductus. It supports existing recommendations that all pregnant women with diabetes should be offered a specialist fetal echocardiogram. This advice is reinforced by published evidence that antenatal diagnosis of cardiac malformations leads to an improved postnatal outcome.

\section{Conclusion}

It could be concluded from this study that IDM is a significant risk factor for CHD. Echocardiogram may be used as an effective tool to diagnose CHD in infants of diabetic mother. Patent foramen ovale and PDA were the commonest cardiac anomalies observed in this study. But to validate this observation larger studies are required.

\section{Conflict of interest: None}

\section{References:}

1. Hoffman JIE. Incidence, mortality and natural history. In: Anderson RH, Baker EJ, Macartney FJ, et al, eds. Paediatric cardiology, 2nd ed. London: Churchill Livingstone, 2002:111-39.

2. Buskins E, Grebe DE, Frohn-Mulder IME, et al. Aspects of the aetiology of congenital heart disease. Eur Heart J 1995;16:584-7.

3. Pedersen LM, Tygstrup I, Pedersen J. Congenital malformations in newborn infants of diabetic women. Correlation with maternal diabetic vascular complications. Lancet 1964;1124-6.

4. Pedersen J, Pedersen LM. Prognosis of the outcome of pregnancies in diabetics. Anew classification. Acta Endocrinol 1965; 50: 70-8.

5. Pedersen J, Pedersen L M, Anderson B. Assessors of fetal perinatal mortality in diabetic pregnancy. nalysisof1,332 pregnancies in the Copenhagenseries. Diabetes 1974;23:302-5.

6. Karlsson K, Kjellmer I. The outcome of diabetic pregnancies in relation to the mother's bloodsugar level. Am J Obstet Gynecol 1972;112:213-20.

7. Chung CS,Myrianthopos NC. Effects of maternal diabetes on congenital malformations. Birth defects 1975; 11:23-58

8. Frier BM, Fisher M, Diabetes Mellitus. In: Nicholus AB, Nicki R C, Brian RW(eds) Davidsons's Principles and Practice of Medicine, $21^{\text {st }}$ edition. Churchil Livingstone. Edinburg ; 2010;p 798-806

9. Buskins E, Grebe DE, Frohn-Mulder IME. Aspects of the aetiology of congenital heart disease. Eur Heart J 1995;16:584-7.

10. Pedersen LM, Tygstrup I, Pedersen J. Congenital malformations in newborn infants of diabetic women. Correlation with maternal diabetic vascular complications. Lancet 1964;i:1124-6

11. Mitchell SC, Sellman AH, Westphal MC. Etiological correlates in a study of 56,109 births. Am J Cardiol 1971;28:653-7.

12. Gladman G, McCrindle BW, Boutin C. Fetal echocardiographic screening of diabetic pregnancies for congenital heart disease. Am J Perinatol1997;14:59-62. 
13. Meyer-Wittkopf M, Simpson JM, Sharland GK. Incidence of congenital heart defects in fetuses of diabetic mothers: a retrospective study of 326 cases. Ultrasound ObstetGynaecol1996;8:8-10.

14. Wren C, O'Sullivan JJ. Survival with congenital heart disease and need for follow up in adult life. Heart 2001;85:438-43.

15. Mills JL, Baker L, Goldman AS. Malformations in infants of diabetic mothers occur before the seventh gestational week: Implications for treatment. Diabetes 1989; 28:292-293

16. Mills JL .Malformations in infants of diabetic mothers. Teratology 1982;25:385-394

17. Reller MD, Tsang RC, Meyer RA. Relationship of prospective diabetes control in pregnancy to neonatal cardiorespiratoryfunction. J Pediatr 1965; 106:86-90
18. Rowland TW, Hubbell JP, Nadas AS.Congenital heart disease in infants of diabetic mothers. J Pediatr1973; ):815-820

19. Shields LE, Gan EA, Murphy HF. The prognostic value of hemoglobin A1c in predicting fetal heart disease in diabetic pregnancies. ObstetGynecol 1993; 81:954-957

20. Soler NG, Soler SM, Malins JM. Neonatal morbidity among infants of diabetic mothers. Diabetes Care 1978; 1:390

21. Way GL, Wolfe RR, Eshagpour E. The natural history of Hypertrophic cardiomyopathy in infants of diabeticmothers. J Pediatr 1989; 95:10201025

22. Weber HS, Copel JA, Reece EA. Cardiac growth in fetuses of diabetic mothers with good metabolic control. JPediatr 1991; 118:103-110 